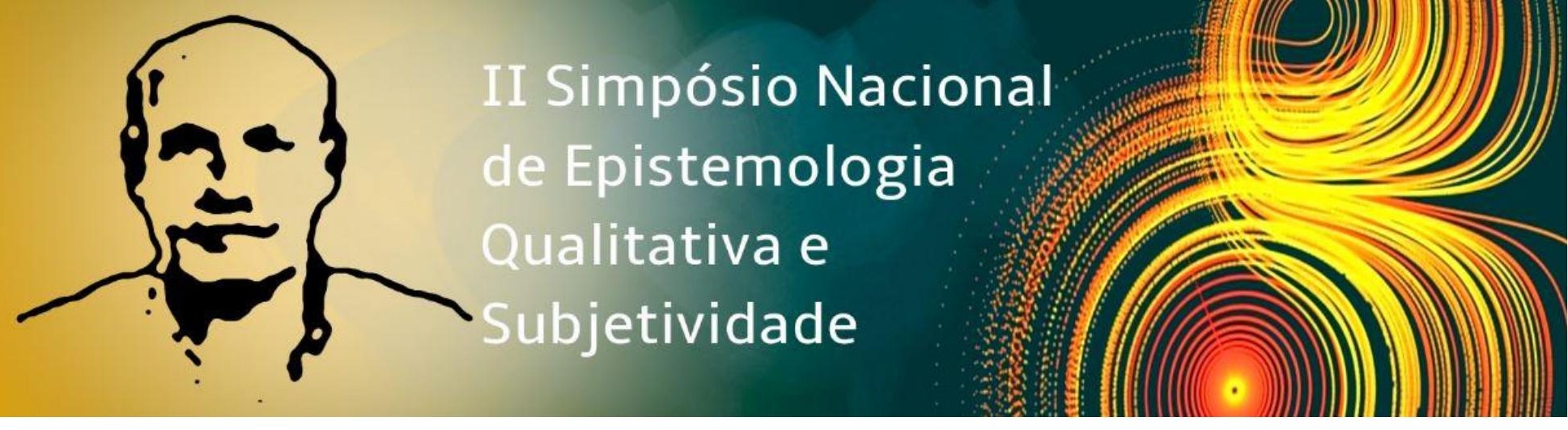

Eixo temático: O trabalho pedagógico e a didática desde a perspectiva da subjetividade

\title{
Educação Sexual na Escola: a construção do processo dialógico e a produção de sentidos subjetivos sobre sexualidade
}

Pedro Raimundo Mathias de Miranda, Universidade Federal do Acre, pr_mathias@yahoo.com.br José Moysés Alves, Universidade Federal do Pará, jmalves@ufpa.br

\section{Resumo}

$\mathrm{Na}$ presente pesquisa, de abordagem qualitativa e com base na Teoria da Subjetividade, investigamos como se configuram os sentidos subjetivos de adolescentes sobre a sexualidade durante o trabalho pedagógico em sala de aula com foco na educação para a sexualidade. $\mathrm{O}$ objetivo foi compreender aspectos de como estudantes do Ensino Médio de uma escola pública de Rio Branco, Acre, subjetivam questões relacionadas à sexualidade, no contexto de práticas educativas dialógico-problematizadoras, com base na abordagem emancipatória de Educação Sexual. Neste recorte da pesquisa, analisamos as informações produzidas em quatro (4) encontros com os/as participantes para dialogarmos, por exemplo, sobre o que é sexualidade, seus componentes e como uma pessoa a expressa no seu cotidiano. A produção das informações ocorreu por meio de conversações em grupo, conversas individuais e complemento de frases. A análise das informações obedeceu ao preceito construtivo-interpretativo, por meio da construção de indicadores e hipóteses sobre os aspectos subjetivos de três (3) estudantes adolescentes (Marília, Sofia e Joaquim, nomes fictícios) relacionados à sexualidade, durante o trabalho de campo/pedagógico em sala de aula. Os resultados indicam que, de modo geral, para Joaquim, Marília e Sofia, a sexualidade equivale à "orientação sexual", genitalidade e/ou relação sexual (sentido restrito), subjetivados no contexto e nas experiências ao longo de suas histórias de vida. A prática dialógica-problematizadora juntamente com o uso de diferentes recursos didáticos possibilitou a reflexão e o processo dialógico dos/as referidos/as participantes da pesquisa, contribuindo para a produção de sentidos subjetivos relativos à sexualidade (sentido amplo), enquanto uma dimensão humana dinâmica, complexa e subjetiva que inclui sentimentos e interações humanas e se expressam nas representações individuais e sociais, como o afeto, a cumplicidade, o prazer etc., envolvendo ou não o fenômeno eróticosexual.

Palavras-chave: Sexualidade. Epistemologia Qualitativa. Abordagem Emancipatória. 


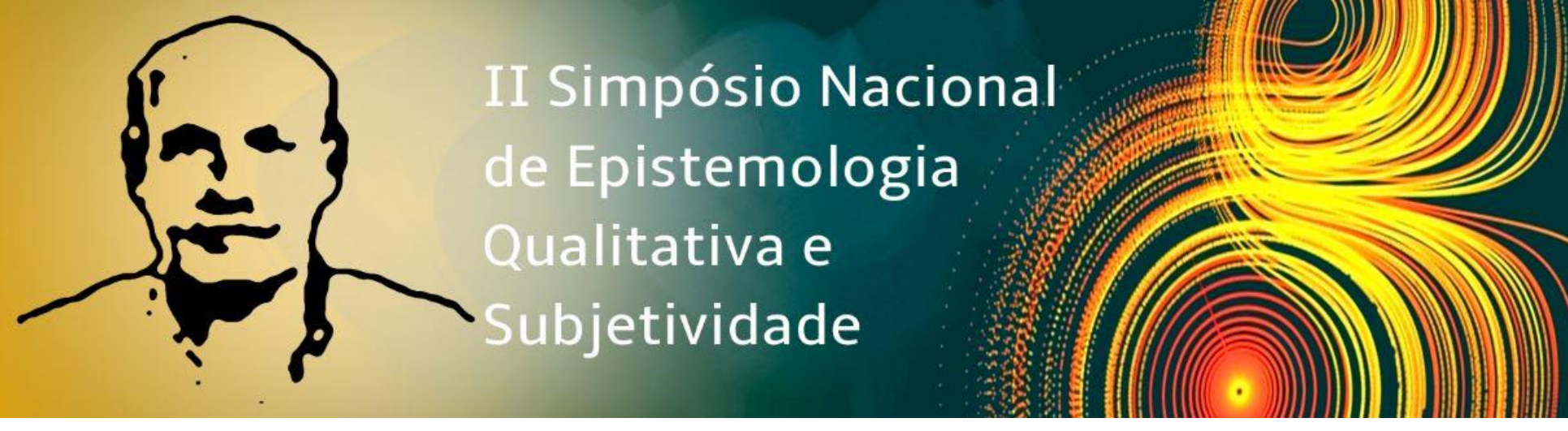

\section{Introdução}

Desde a infância recebemos informações sobre a sexualidade nos diversos contextos em que vivemos por via direta e indireta, de modo intencional e não intencional, com base em crenças, valores, costumes e normas sociais e religiosas, que evidenciam aspectos históricos e culturais de um povo ou sociedade. Assim, em sentido amplo, a educação sexual consiste em toda e qualquer referência à sexualidade realizada pela família, na escola, na igreja, nas conversas entre amigos/as, por meio da mídia etc., em que gestos, palavras, olhares, expressão de sentimentos, sensações em relação ao próprio corpo e relacionamentos fornecem “elementos" que são/serão subjetivados pelo sujeito na construção da própria sexualidade (TUCKMANTEL, 2011).

Ao longo do desenvolvimento biopsicossocial do ser humano, o modo como as questões da sexualidade foi/é subjetivado reflete na forma como a pessoa se reconhece, expressa e vivência sua sexualidade. Dessa perspectiva, se a educação sexual (intencional e não intencional) na escola se constituir um espaço de diálogo e orientação às crianças e adolescentes sobre as questões da sexualidade e gênero, muito provavelmente, eles/as construirão uma visão e referência positiva de si mesmos/as, consciente e responsável com a própria sexualidade “[...] de maneira saudável, prazerosa, bonita, natural e essencial em nossas vidas" (BONFIM, 2012, p. 97).

Para este estudo, adotamos como referenciais teóricos a Teoria da Subjetividade de González Rey (2003, 2005) com foco processo de ensino e aprendizagem (GONZÁLEZ REY, 2008, 2012) e a abordagem emancipatória de educação sexual (FIGUEIRÓ, 2010; FURLANI, 2011), que valorizam o debate, a reflexão e a reconstrução de saberes e conceitos. Para a referida abordagem, a prática dialógica visa promover a compreensão de valores, rótulos, preconceitos, dúvidas e sentimentos em torno das questões da sexualidade e o entendimento de como os padrões e normas sexuais estão relacionados com a história, a cultura, a política e a estrutura socioeconômica de uma sociedade. Tem ainda a finalidade de auxiliar o sujeito (que aprende) na leitura e compreensão da própria sexualidade, como ela foi e é instituída nas relações sociais, os movimentos de repressão, a necessidade de participação nas lutas por mudanças de normas e valores relacionados à expressão e vivência da sexualidade (FIGUEIRÓ, 2010). 


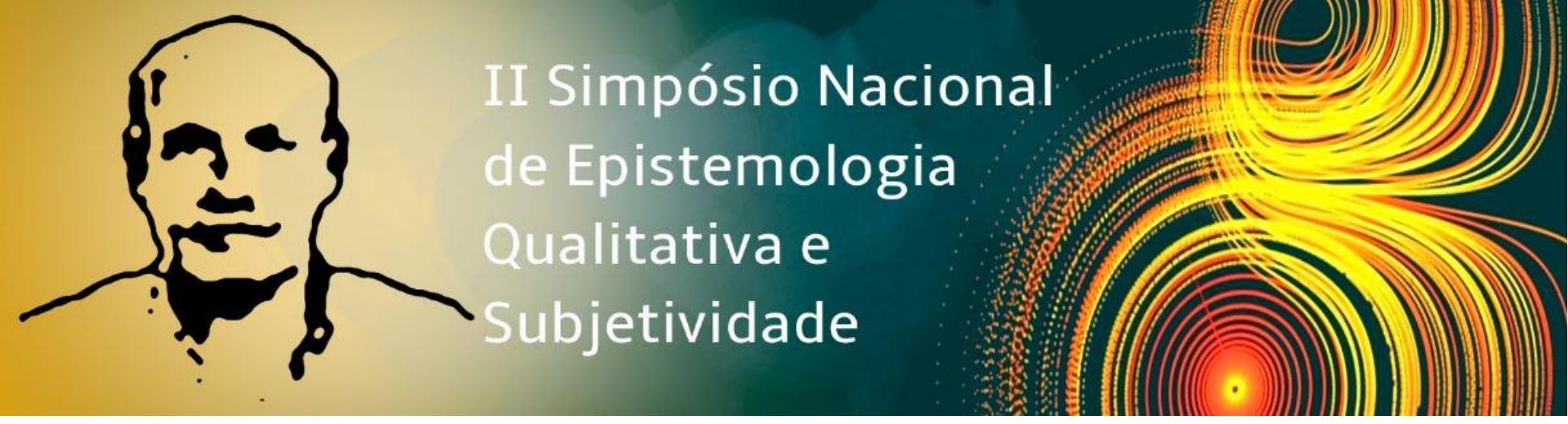

Concordamos com Maia (2004) quando sugere que uma proposta de educação sexual forneça informações em um espaço que se possa realizar reflexões e questionamentos sobre a sexualidade, bem como ir além da mera informação, como meio de promover e garantir uma educação sexual abrangente.

Entendemos a sexualidade como uma dimensão humana complexa e subjetiva, que se desenvolve nas relações interpessoais e se expressa nas atitudes e representações sociais e individuais, envolvendo ou não o fenômeno erótico-sexual. Inclui também, a busca pelo prazer, bem-estar e cumplicidade e se manifesta por meio de pensamentos, sentimentos e atitudes, bem como, nas práticas erótico-sexuais (BONFIM, 2012; MAIA, 2011).

Ao propor integrar a subjetividade ao processo de ensino e aprendizagem na escola, González Rey (2008, p. 33) considera que a produção de sentidos subjetivos acrescenta qualidade à aprendizagem, pois “[...] o sujeito aprende como sistema e não só como intelecto". Ao desenvolver a categoria sujeito que aprende, o referido autor faz referência às configurações subjetivas envolvidas no processo de aprendizagem pelo envolvimento e iniciativa do/a aluno/a, com o desenvolvimento de operações e aplicação do que foi aprendido em novas situações, conferindo-lhe importância no desenvolvimento pessoal (GONZÁLEZ REY, 2012).

A sexualidade como produção subjetiva perpassa todo o desenvolvimento humano e resulta de um sistema de sentidos subjetivos organizados em diferentes configurações subjetivas particulares, cujas significações e vivências resultam de uma configuração dinâmica e dialética entre o individual e o social, nos diferentes espaços sociais que ocupa (GONZÁLEZ REY, 2003; FIGUEIRÓ, 2014). Para o contexto desta pesquisa ${ }^{1}$, os sentidos subjetivos relacionados à sexualidade resultam de unidades simbólico-emocionais, que emergem em diferentes contextos em torno das questões da sexualidade, em sentido amplo.

A pesquisa ${ }^{1}$ teve por objetivo geral compreender aspectos de como estudantes do Ensino Médio de uma escola pública de Rio Branco, Acre, subjetivam questões relacionadas à

\footnotetext{
${ }^{1}$ Pesquisa de doutorado do primeiro autor, intitulada Educação Sexual na Escola: sentidos subjetivos do sujeito que aprende em uma escola pública de Rio Branco - Acre, pelo Programa de Pós-Graduação em Educação em Ciências e Matemática da Universidade Federal do Mato Grosso e Rede Amazônica de Educação em Ciências e Matemática - REAMEC, polo Universidade Estadual do Amazonas.
} 


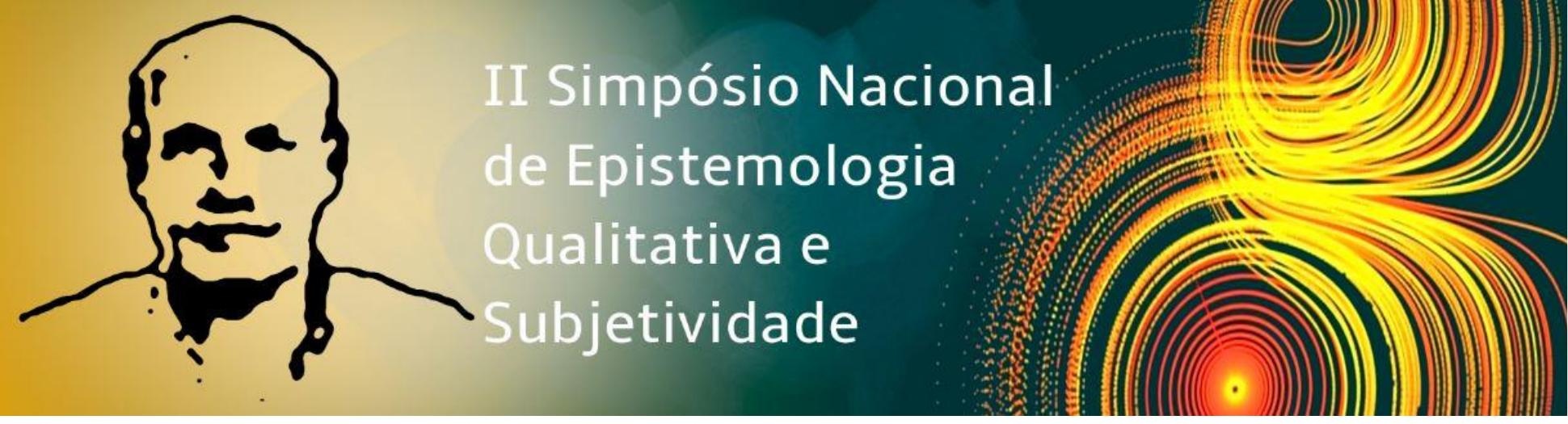

De modo geral, a sexualidade foi relacionada aos caracteres biológicas que diferenciam o homem e a mulher por meio do seu sexo biológico, à "opção sexual", isto é, a orientação sexual, à atração por pessoas, características e/ou comportamentos, o desejo e o prazer relativos ao ato sexual.

Para algumas problematizações, a exemplo, se uma criança tem sexualidade e como alguém constrói sua sexualidade na interação com o seu grupo social, não obtivemos respostas, argumentos contrários e/ou questionamentos em relação às questões/ideias apresentadas. Quanto aos componentes da sexualidade, os/as participantes fizeram menção apenas ao componente biológico (órgãos genitais) como fator que determina a "sexualidade" de uma pessoa, isto é, ser homem (masculino) ou ser mulher (feminino).

$\mathrm{Na}$ conversação em grupo (CG) sobre o que é a sexualidade, Joaquim (15 anos) considerou que é "atração e quais características de outras pessoas são atraentes para você" e que uma pessoa manifesta sua sexualidade "quando alguém sente desejo, atração por determinadas características, pessoas" (CG).

Sofia (15 anos), disse que "a sexualidade é a identificação pessoal em relação a quem ou como você sente atração por outras pessoas [...] se relaciona diretamente com as outras pessoas, como por exemplo: ser homossexual, transexual" (CG).

Para Sofia e Joaquim (assim como para outros/as participantes da pesquisa), a sexualidade corresponde à orientação sexual, isto é, o desejo e/ou a atração que alguém sente por uma pessoa e com a qual poderia estabelecer um relacionamento afetivo e/ou sexual. A orientação sexual define, basicamente, a identidade sexual e de gênero de uma pessoa. Nos Princípios de Yogyakarta, um documento encaminhado às Nações Unidas sobre a aplicação da legislação internacional de Direitos Humanos em relação à sexualidade, a orientação sexual é definida como a "[...] capacidade de cada pessoa experimentar uma profunda atração emocional, afetiva ou sexual por indivíduos de gênero diferente, do mesmo gênero ou de mais de um gênero, assim como de ter relações íntimas com essas pessoas" (INDONÉSIA, 2006, p. 10).

Quanto a sexo e sexualidade, Marília (15 anos) afirmou que "sexo se refere mais à relação sexual e sexualidade ao prazer, atração, desejo" (CG). No decorrer da conversação 


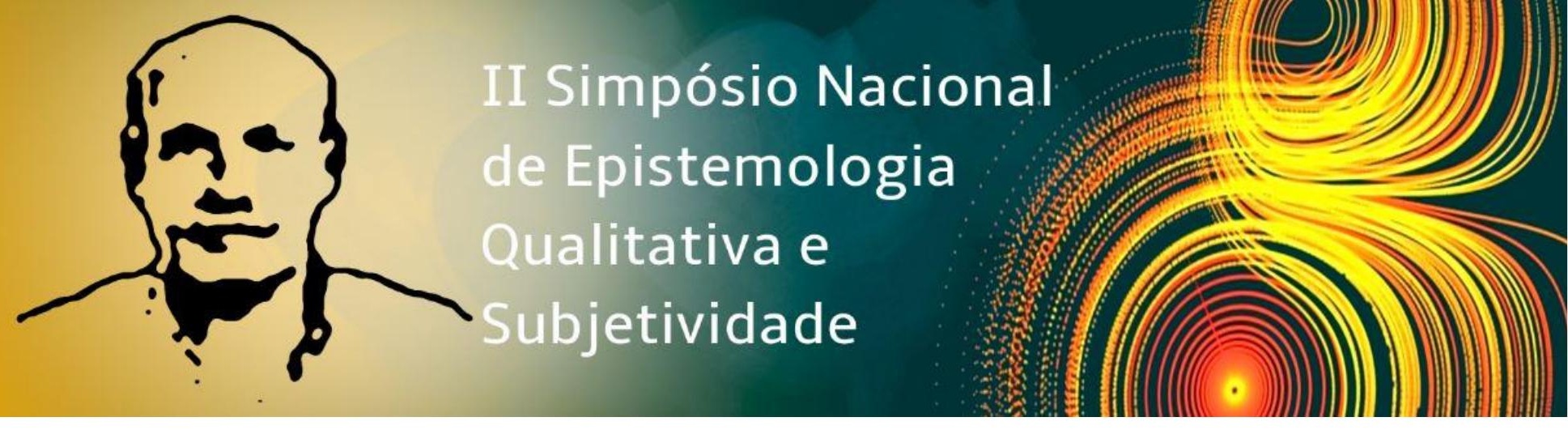

sobre se as pessoas idosas têm sexualidade, a participante disse que "[...] todas tem vontade de alguma coisa". Ao questioná-la sobre que vontade fazia referência, respondeu: "se for sexualidade, tem vontade e desejos" (CG).

De que vontade e desejo Marília falava? De algo que não pode ser dito em público? De algo que não se fala com quem não se tem confiança e intimidade? Seriam as questões e comentários impróprios ao trabalho pedagógico em sala de aula?

Estamos inseridos e "vivemos em um ambiente "sexualizado" e os discursos sobre a sexualidade entrelaçam todas as esferas da nossa vida cotidiana: confusos, apelativos, questionantes, mistificadores e enquadradores [...]" (NUNES, 2005, p. 13) determinando comportamentos e provocando tensões entre o que pode ser dito e não dito.

No contexto em que as informações foram produzidas e devido à falta de definição e de complemento, os termos vontade, desejo e atração foram tomados como indicadores de sentidos subjetivos de sexualidade como fenômeno erótico, com o sentido de atração, desejo de aproximação e contato físico e, enfim, a relação sexual. A concepção de que falar sobre sexualidade é falar de sexo, resulta de uma visão restrita da mesma, com base em crenças e valores que concebem o sexo e a sexualidade como sinônimos e como algo imoral, sujo e pecaminoso (BONFIM, 2012).

Por ser a sexualidade um tema envolto em muitos mitos e tabus, o trabalho pedagógico em sala de aula, pode provocar insegurança, vergonha e/ou inquietação nos/nas adolescentes por considerarem que falar de sexualidade é falar de sexo, de intimidade, dizer sacanagens, isto é, fazer comentários libidinosos e imorais relacionados a desejos e/ou atos sexuais. Esse sentimento está relacionado à concepção de sexualidade genitalizada e com foco na relação sexual, que constitui a subjetividade social de muitas famílias, escolas e outras instituições sociais em relação à abordagem das questões da sexualidade na escola.

No contexto desta pesquisa, consideramos a subjetividade social como o campo de sentidos contraditórios de representações hegemônicas e contra hegemônicas sobre a sexualidade e, por subjetividade individual, o conjunto de experiências resultante da história de vida relativas à própria sexualidade, bem como, o compartilhamento de crenças e valores 


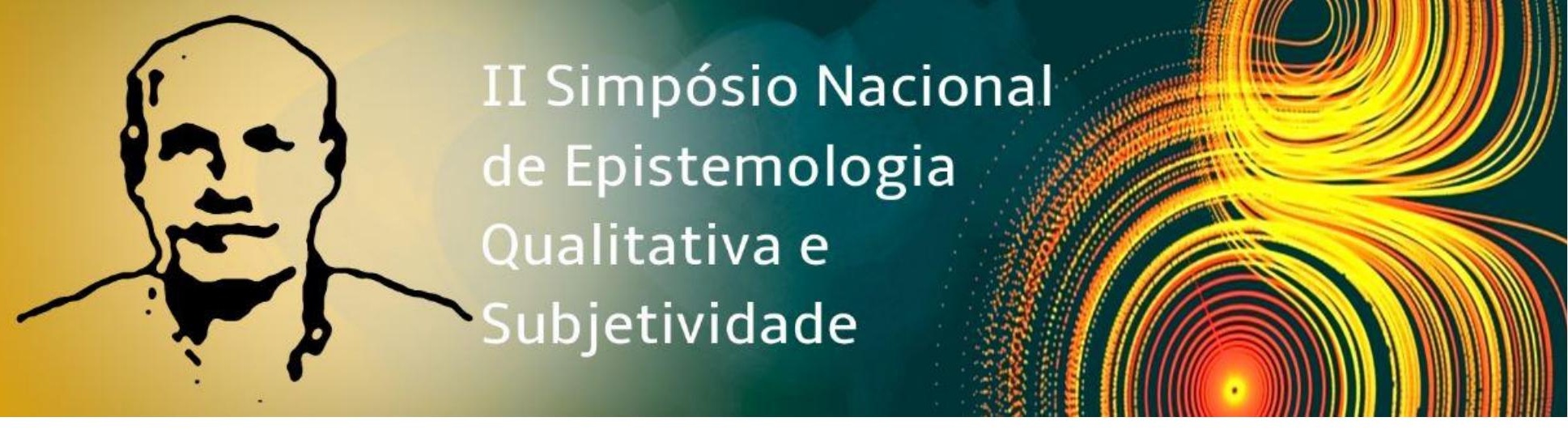

sociais que tem por base a história e a cultura da sociedade onde se deu o desenvolvimento biopsicossocial do sujeito.

Por ser um tema complexo, falar de sexualidade envolve a necessidade de conhecer termos, definições e significados, bem como, aspectos dos componentes biológico, psicológico, social, histórico e cultural que a constitui. Percebemos que a participação dos/as estudantes demandava a compreensão e aprendizagem de termos, conceitos e/ou definições a exemplo de: macho, fêmea e intersexo relativos a sexo biológico, homem e mulher cisgênero, homem e mulher transgênero, heterossexual, homossexual e bissexual, relacionados a gênero, orientação sexual e a definição de sexualidade, em sentido amplo.

No intuito de possibilitar a reflexão e a produção de sentidos subjetivos das questões apresentadas, adotamos como definição de sexualidade, a dimensão presente em todas as relações humanas que envolvem prazer, bem-estar, alegria, carinho, bem-querer, contato físico, intimidade, comunicação, comportamentos e atitudes, envolvendo ou não o fenômeno da prática sexual (BONFIM, 2012; FIGUEIRÓ, 2009; FURLANI, 2011).

Consideramos ainda a necessidade dos/as participantes se acostumarem com a abordagem do tema no sentido de ouvir, problematizar e administrar suas concepções e emoções. Por outro lado, à medida que compreendiam a dinâmica das atividades, ficaram mais à vontade, ganharam confiança para expor suas ideias, fazer questionamentos e conversar com os/as colegas.

Melo e Kornatzki (2013, p. 11) afirmam que "o ser humano é um ser de relações, pois as constrói e é construído pelo movimento dialético da vida que as constitui [...]". Dessa perspectiva, percebemos que à medida que as informações eram produzidas e retomávamos para dar continuidade as conversações com o grupo, ganhava força o processo dialógico pela confiança e empatia entre os/as participantes e destes/as com o professor-pesquisador, com segurança e envolvimento emocional com o tema. Nesse processo, identificamos que as problematizações, juntamente com as dúvidas, informações e explicações geravam nos participantes um falar do outro e para o outro e ao mesmo tempo um falar de si e para si mesmo, promovendo assim o processo reflexivo e de subjetivação de acordo com as experiências, crenças e valores de cada um/a. 


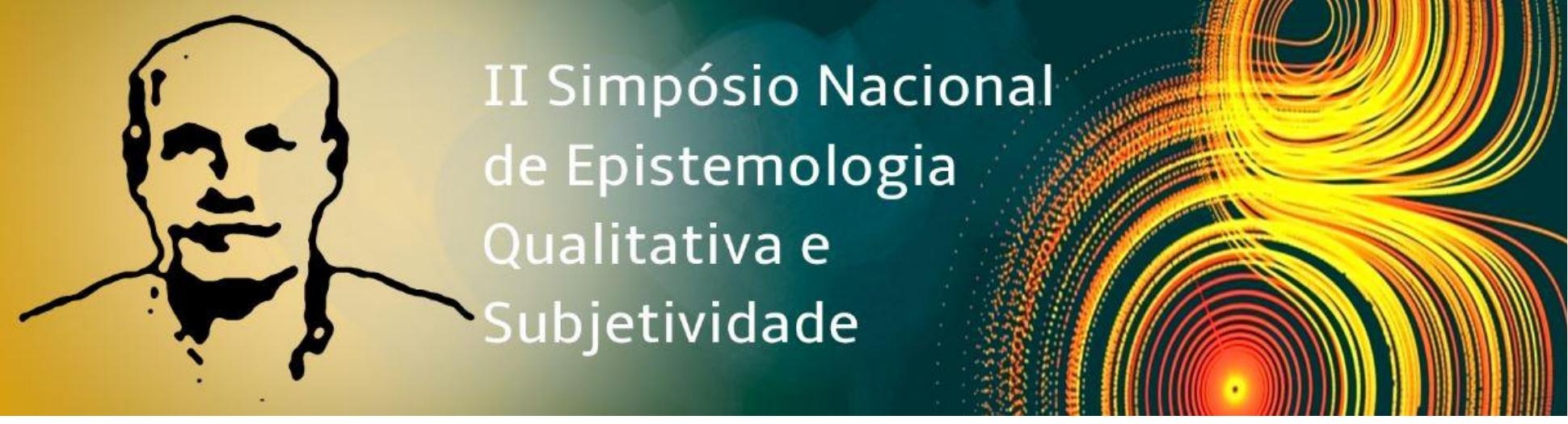

Nas conversações sobre as diferentes formas de expressão da sexualidade (sentido amplo), Marília afirmou que " a sexualidade não se resume somente a uma atração pelo homem ou uma mulher. Ela se resume também ao prazer, [por exemplo] o prazer de conversar com amigos, em uma roda de amigos" (CG).

No Complemento de Frase 2 (CF 2), asseverou que vivencio minha sexualidade quando estou em uma roda de conversa com amigos e que a sexualidade não se limita só a sexo, inclui afeto, abraçar alguém que gosta, atração, desejo. Assim, Marília passou a considerar que a sexualidade (sentido amplo) está presente em diferentes momentos de sua vida, como aqueles que envolve a vivência de relações afetivas como a amizade, assim como, o bemestar e o prazer que um abraço e o estar com os/as amigos/as podem lhe proporcionar.

Sofia considerou que a sexualidade é personalidade, é um conceito complexo, envolve sexo, orientação afetivo-sexual ... [reticências da participante] e que, vivencio minha sexualidade me aceitando, convivendo com outras pessoas, falando sobre ela (CF 2). Ao fazer referência às relações interpessoais que envolve diálogo e autoaceitação, Sofia aponta aspectos de como na interação com seu grupo social constrói dialeticamente e de modo subjetivo sua sexualidade, pela recursividade subjacente entre a subjetividade individual e a subjetividade social dessa dimensão humana. É nas relações sociais que o sujeito descobre e se dá conta da sua sexualidade (identidade de gênero e orientação sexual), aprende e reaprende, constrói e reconstrói sua sexualidade, como componente fundamental da personalidade.

$\mathrm{Na}$ conversa individual (CI), Sofia contou que os debates possibilitaram fazer a diferenciação entre identidade de gênero, orientação sexual e expressão de gênero. Reconheceu que antes das atividades, sabia que havia uma ligação entre esses termos e definições, mas, "se me perguntassem a diferença de cada um exatamente, eu não saberia" (CI). Evidenciou assim, o valor do processo dialógico no trabalho pedagógico de educação sexual intencional na escola, como facilitador da aprendizagem pela mobilização e produção de sentidos subjetivos relativos ao tema abordado.

Para Joaquim, a sexualidade é algo complexo, único em cada ser. Pode ser definida como “prazer”. Sexualidade não é só sexo [aspas do participante]. Também, que sente prazer [em] tocar violão, ouvir música, sair com amigos, ter momentos bons (CF 2). Na conversação 


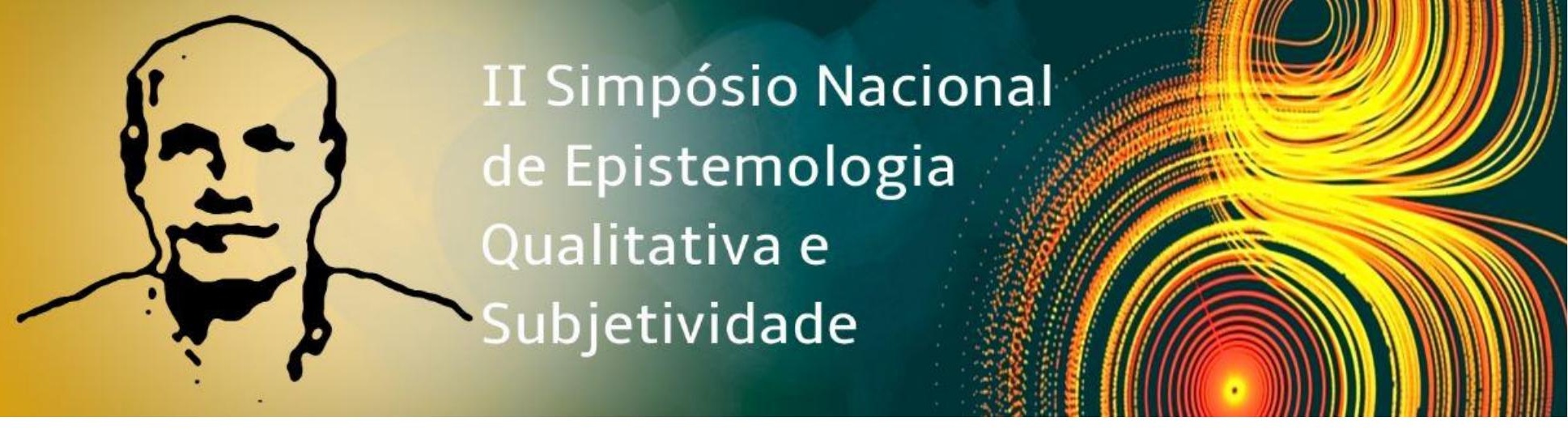

individual, afirmou que as atividades contribuíram para “[...] abrir mais a minha mente sobre a ideia do que é a sexualidade, que não é algo simples! Antes eu pensava que sexualidade era somente relação sexual e aqueles termos ... [pausa]. É, não é opção! Essas coisas”. Acrescentou ainda que "[...] se eu tivesse esse conhecimento antes, eu teria feito escolhas diferentes na minha vida em questão de relacionamentos" (CI).

Ao estabelecer relação entre o que foi discutido e suas experiências, Joaquim passou a considerar que a sexualidade está presente nos momentos de sua vida em que sente prazer, como tocar violão e estar com os/as amigos/as. Provavelmente, para o participante, esses aspectos não tinham relação com a sexualidade, enquanto uma dimensão complexa, subjetiva e "um dos núcleos estruturantes que formam a totalidade humana [...]” (BONFIM, 2012, p. 27).

\section{Considerações Finais}

Consideramos que, inicialmente, a construção do espaço de diálogo e reflexão para mobilização e produção de sentidos subjetivos sobre a sexualidade, foi marcada por "dificuldades" devido à falta de informações dos/as participantes sobre o tema/questões propostas. No entanto, entendemos que pela perspectiva da subjetividade, as "dificuldades" têm relação com o processo subjetivo de construção da sexualidade como algo definido pelo componente biológico (órgãos genitais e hormônios sexuais) e que condiciona o gênero e a orientação afetivo-sexual de uma pessoa (subjetividade social da família e da escola).

De modo análogo, a sexualidade como sinônimo de relação sexual, não deve ser objeto de diálogo ou análise pelos/as adolescentes, para não estimular o interesse pela prática sexual, considerada por algumas pessoas e/ou instituições como algo imoral e/ou pecaminoso. Esse aspecto pode ter sido a causa do medo e/ou a vergonha dos/as participante da pesquisa para dialogar sobre o tema, devido às normas, crenças, valores e experiências subjetivadas sobre o falar da sexualidade, assim como, a dificuldade de se reconhecerem como ser-corpo-sexuado no mundo em permanente processo de educação sexual, como propõem Melo e colaboradores (2011).

A sexualidade com o sentido de genitalidade e relação sexual resulta ainda de uma concepção de uma educação sexual prescritiva, que determina o "certo" e o "errado", o que 


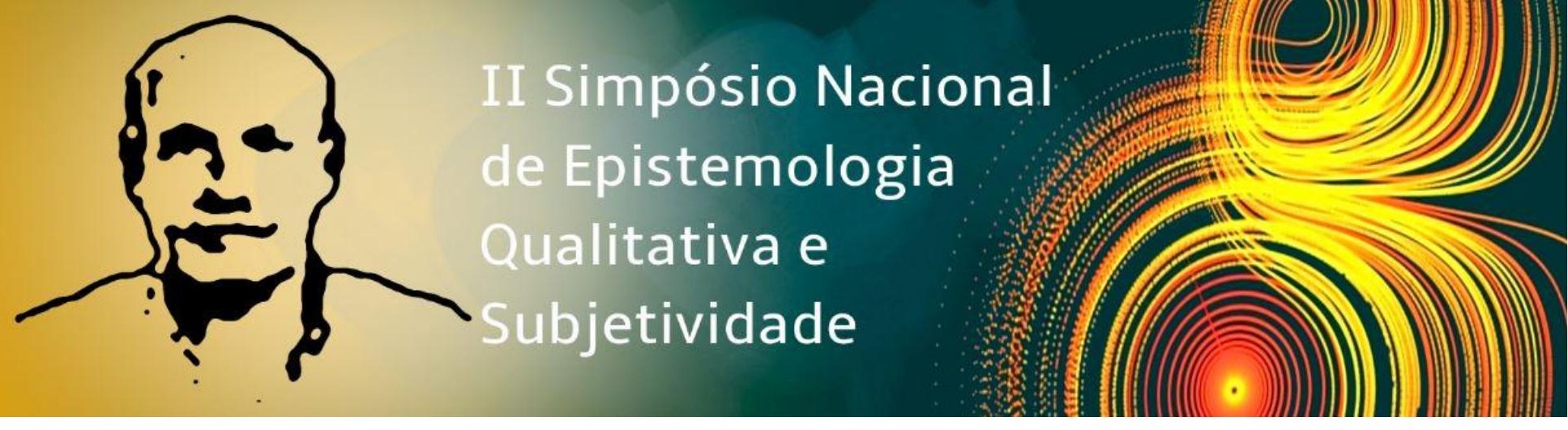

pode ser dito e não dito, sem considerar o contexto sócio histórico e familiar, a história de vida do sujeito, as questões éticas e socioemocionais que constituem os aspectos subjetivos (individual e social) relativas à expressão e vivência da sexualidade, em um determinado grupo social.

As proposições apontadas acima justificam a inexistência, a precariedade e/ou a interdição ao diálogo com crianças e adolescentes sobre o tema na família e na escola, apesar dos inúmeros estudos e orientações técnicas de organizações nacionais e internacionais, como a UNESCO, para a promoção da educação em/para a(s) sexualidade(s), como meio de garantir a formação integral do sujeito, o reconhecimento e a luta por direitos e o pleno exercício de sua cidadania.

A pesquisa/trabalho pedagógico com foco na prática dialógica e reflexiva, considerando o posicionamento crítico do sujeito ante ao que aprende e o processo de aprendizagem como produção subjetiva como proposto por González Rey (2008), contribuiu para "deslocar" os/as participantes da pesquisa de suas "zonas de conforto" em relação ao processo de ensino e aprendizagem, no sentido de romper com passividade ao ouvir, anotar, apreender e reproduzir o conteúdo abordado.

O trabalho recursivo sobre as concepções de sexualidade e seus componentes, como alguém a expressa em seu cotidiano e as outras questões abordadas, utilizando diferentes recursos didáticos foi decisivo no sentido de encorajar os/as participantes a apresentarem e reconhecerem suas concepções e emoções no trato das questões da sexualidade, em um ambiente de reflexão, compartilhamento e construção coletiva da aprendizagem.

Para Marília, Joaquim e Sofia, o processo dialógico proporcionou a mobilização de sentidos subjetivos que, ao longo da realização das atividades foram reconfigurados e/ou produzidos outros sentidos subjetivos em relação à sexualidade, permitindo-lhes enriquecer a compreensão da própria sexualidade. 
